\title{
Leer, Escribir y Comunicarse en Otro Idioma con Nuevas Prácticas Letradas Fuera del Aula de Clase
}

\author{
Sonia Jerez-Rodríguez ${ }^{1}$ y María E. Navas-Rios ${ }^{2}$ \\ (1) Departamento de Idiomas Extranjeros, Universidad de Córdoba, Colombia. \\ (e-mail: sjerez@correo.unicordoba.edu.co) \\ (2) Universidad de Cartagena, Vicerrectoría de Docencia, Programa de Doctorado en Ciencias de la \\ Educación., Colombia (e-mail: mnavasr@unicartagena.edu.co)
}

Recibido Jun. 12, 2018; Aceptado Ago. 13, 2018; Versión final Sep. 27, 2018, Publicado Abr. 2019

\begin{abstract}
Resumen
Se describen y analizan las nuevas prácticas letradas que utilizan los estudiantes de inglés como lengua extranjera fuera del aula de clase y en su vida cotidiana, para comunicarse y aprender. Para tal fin se realizó un estudio de caso con 13 estudiantes en formación docente, en el idioma inglés. La información se obtuvo con fotografías, entrevistas a profundidad y un grupo focal. La sistematización de la información se apoyó en el software Atlas.Ti, y de acuerdo a los resultados se muestra que leer y escribir en otro idioma se convirtió en parte de la cotidianidad de los futuros docentes, permitiéndoles crear e interpretar significado a través de textos digitales, que tenían elementos, lingüísticos, orales y visuales, los cuales les facilitó además interactuar y comunicarse en el idioma que aprenden con otros que están geográficamente distantes.
\end{abstract}

Palabras clave: literacidad; nuevas prácticas letradas; aprendizaje del inglés; TICs

\section{Reading, Writing and Communicating in another Language with New Literacy Practices outside the Classroom}

\begin{abstract}
New literacy practices of students of English as a foreign language outside the classroom and in their daily lives, to communicate and learn are described and analyzed. A case study methodology was followed with 13 future teachers of English. To gather the information the participants collected pictures of what they read and wrote, performed deep interviews and form a focus group. The information was analyzed through the software Atlas.Ti and according to the results, it is shown that reading and writing in another language became part of the daily lives of the participants, and allowed them to interpret meaning from texts that were built from linguistic, oral, or visual elements. At the end, the participants interacted and communicated in the language they learnt, with others who were geographically distant.
\end{abstract}

Keywords: literacy; new literacy practices; texts; english language learning; ICTs 


\section{INTRODUCCIÓN}

Hoy existe acceso a diferentes oportunidades de comunicación que han trascendido el espacio del aula, las cuales son dinámicas, multimodales, situadas y mediadas por las tecnologías digitales, lo cual ha facilitado que nos comuniquemos y aprendamos sobre lo que otros escriben, no solo de manera local sino también global, incluso en diferentes idiomas. Sin embargo, este giro digital no ha implicado abandonar la lectura de libros impresos, periódicos, revistas de papel, la escritura en papel o tomar notas, a veces, con la certeza de que esto es más productivo a usar un computador (Mueller y Oppenheimer, 2014). En cambio, sí ha significado la necesidad de considerar que nos encontramos en un nuevo ciclo de novedades tecnológicas las cuales han permitido el acceso a diferentes formatos y medios, a formas diferentes de leer y escribir, lo que además ha llevado hacer un cambio de prácticas letradas o usos de la lectura y escritura (Zavala, 2008) de la página a la pantalla. Como resultado, este nuevo panorama permite sea en casa, en nuestra comunidad, o en el trabajo continuar leyendo y escribiendo, con una combinación más frecuente entre el papel, lápiz, marcador tablero y otras tecnologías, sin limitar la comunicación a los espacios físicos, permitiendo concebir de manera diferente y muchas veces inconscientemente lo que significa leer y escribir en nuestras vidas. Particularmente y en el caso de quienes son jóvenes, el giro digital también ha permitido que surja una nueva generación de lectores y escritores en diferentes contextos, quienes mantienen nuevas formas de participación a través de prácticas letradas vernáculas (Barton y Lee, 2012), o personales (Haneda, 2006), mientras al mismo tiempo mantienen el uso de prácticas más dominantes o institucionalizadas en la escuela (Street, 2003), para aprender y para convivir en un mundo cada más globalizado. Es decir, estén en o fuera del aula de clase, leen y escriben para distintos usos y dominios, en diferentes idiomas, en su vida diaria, de manera impresa o mediadas por nuevas tecnologías, creando significado a través de diferentes textos que comparten a través de diversos medios y formatos.

Por lo anterior, este estudio escogió indagar sobre las nuevas prácticas letradas que mantienen en inglés y fuera del aula, los estudiantes de un programa de licenciatura en idiomas extranjeros y futuros docentes, e identificar de qué manera éstas les permiten comunicarse en el idioma inglés, más allá del aula de clase y aportan a su aprendizaje. El estudio se justifica atendiendo a tres premisas: la primera se relaciona con el imaginario por parte de los docentes, de considerar pérdida de tiempo lo que hacen los estudiantes fuera del aula de clase al leer y escribir, desconociendo el posible aporte al aprendizaje del idioma inglés (Jerez, Mercado y Viloria, 2015). La segunda premisa tiene que ver con la enseñanza del inglés en Colombia, ya que este idioma se enseña como lengua extranjera y las oportunidades de usarlo fuera del aula con otras personas que también lo hablen son escasas (Herazo, Jerez y Lorduy, 2012, p. 2008). La tercera premisa, es la forma como se concibe la literacidad centrada en lo lingüístico y cognitivo en el aula, dejando atrás lo que significa leer y escribir como práctica social, sin valorar que en el contexto comunicativo actual los jóvenes están involucrados con prácticas letradas menos convencionales, las cuales son nuevas por el "elemento técnico" que poseen, y su "carácter distintivo" (Knobel y Lankshear, 2014, p 98), lo que las hace más colaborativas, participativas, multimodales, distribuidas, menos individuales, y permiten nuevas formas de comunicación.

En otras palabras, sus experiencias con la lectura y la escritura fuera del aula les permiten actuar en el idioma inglés, con otros además de sus compañeros y docentes, permitiéndoles crear como lo sustentan Acosta y Poveda (2014, p.4) comunidades de aprendizaje estrechamente ligadas al concepto de trabajo colaborativo y a las tecnologías de la información y comunicación, rompiendo los escenarios formativos limitados a las instituciones escolares. Demostrando que actualmente existe una relación cercana entre literacidad y las nuevas tecnologías de la informática y la comunicación, sin que sean las herramientas tecnológicas por si solas las que promueven un cambio o una innovación en las formas de leer y escribir, y son tan solo un medio más, a través del cual se dan nuevos aprendizajes. De ahí que hablar de literacidad y en palabras de Kern (2000, p.23) significa la "interpretación y creación de significados a través de diferentes textos", los cuales y debido al nuevo panorama tecnológico se presentan en diferentes modos y formatos. Por lo anterior, se deberá tener en cuenta y desde el aula, que las comunicaciones escritas que los jóvenes mantienen actualmente en otro idioma si bien son muy digitales e incluyen diferentes recursos tecnológicos y semióticos, ante todo contribuyen a renovar el concepto de literacidad más allá de dos habilidades independientes como son leer y escribir. Las nuevas prácticas letradas se convierten entonces en un recurso promisorio para apoyar el aprendizaje y la comunicación en otro idioma, ya que le exige a los jóvenes ser consumidores y también productores de textos tanto en su vida académica como en su vida diaria fuera del aula.

Indagar sobre este tema es coherente y valioso para quienes escriben las políticas públicas de enseñanza de otro idioma y para quienes son docentes o lo serán en un futuro, ya que ante todo se trata de ir más allá de solo explorar el uso de nuevas tecnologías en el aula, y los beneficios que engendran para el aprendizaje, y en cambio tiene que ver con identificar qué hacen por su propia cuenta cuando leen y escriben los futuros docentes fuera del aula, y cómo esto aporta al desarrollo de su literacidad en el idioma que aprenden. Teniendo en cuenta además que leer y escribir en otro idioma como el inglés no son solo se aprenden en el aula de clase, y también hacen parte de las actividades sociales de la vida diaria llegando incluso a transformar o complementar su aprendizaje y futura enseñanza durante su práctica profesional docente. 


\section{OTROS ANTECEDENTES: LITERACIDAD}

La definición de literacidad que se presenta en este estudio va más allá del enfoque lingüístico y cognitivo y significa siguiendo a los Nuevos Estudios de Literacidad (NEL) (Street 1984; Barton y Hamilton, 1998; Gee 1996), como representantes de una nueva tradición, la existencia de una forma adicional de comprenderla, desde una perspectiva social. Esta nueva mirada se ha venido desarrollando desde la década de los años 80 principalmente en Inglaterra, y con estudios en Latinoamérica e Iberoamérica (Viñao, 1998; Zavala, 2008; Mora, 2014, Lorenzatti, 2014; López Bonilla y Fragozo, 2013) que se identifican con el modelo ideológico de Street (1984). En este sentido, los NEL muestran un enfoque diferente al tradicional, ya que se pensaba que la literacidad era un fenómeno mental o cognitivo únicamente, y este movimiento presenta el significado de leer y escribir en relación con lo que la gente hace en el mundo o en la sociedad, es decir, la lectura y la escritura como práctica, o actos socioculturales a través de los cuales los ciudadanos desarrollan una actividad vital en una comunidad letrada, de manera integral en todos sus contextos y prácticas, es decir en lo social, cultural, histórico e institucional.

Por lo cual, la perspectiva de los NEL ofrece un nuevo significado de literacidad, reconociendo que existen diferentes tipos de prácticas letradas en las que la gente se involucra y en varios ámbitos sociales como la comunidad, el hogar, la iglesia, y el trabajo (Barton y Hamilton, 1998). Así, leer un menú, una imagen, leer o escribir un mensaje de texto en una red social, son todas consideradas prácticas letradas tanto como escribir resúmenes, leer libros en la escuela o hacer presentaciones académicas. Es decir, que se puede considerar la interacción de los estudiantes con los textos visuales, impresos, digitales, orales, tales como ver videos, jugar videojuegos, por ejemplo, como diferentes tipos de prácticas letradas porque de todas maneras lo que se hace es usar el conocimiento letrado que se tiene y las habilidades para leer o escribir un texto. Además, estas prácticas siempre ocurren en contextos situados o específicos (Gee, 2004) y son sociales porque involucran formas reconocidas de hacer algo con la lectura y la escritura (Zavala, 2008). Un clásico ejemplo es el cuento, el cual puede ser leído en el aula usando un libro impreso, pero también en casa y de maneras diferentes, puede ser en el computador o celular, y donde la práctica de leer libros se vuelve significativa para quien la usa. Así, leer y escribir va más allá de dos habilidades lingüísticas, privadas, cognitivas y también se hacen sociales porque lo que se hace finalmente es interpretar los textos que recibimos y crear nuevos textos para compartir con otros, con el objetivo de comunicarnos. Es decir que las nuevas prácticas letradas tienen ese beneficio y es que leer y escribir nunca había sido tan social como lo es actualmente.

De igual manera y teniendo en cuenta que este estudio se realiza con jóvenes y futuros docentes se llevó a cabo una revisión bibliográfica, hallándose en primer lugar, que el tema de las prácticas letradas de los jóvenes fuera del aula ha venido siendo investigado entre quienes aprenden otro idioma. Por ejemplo, Black (2005) usando un marco teórico de los NEL, reportó el uso de Fanfiction.net, como el más amplio archivo que reúne participantes en Norte América, Asia y Europa interesados en recrear sus propias narrativas interactivas basadas en libros, películas, libros o video juegos, interactuando de formas sofisticadas en actividades de escritura en otros idiomas. Igualmente, Fukunaga (2006) en su estudio con jóvenes estudiantes norteamericanos para aprender el idioma japonés y su cultura de manera divertida y espontánea siguió el uso del "manga". Los dos estudios coincidieron en que pertenecer a una comunidad de discurso donde las actividades realizadas acompañan la producción y negociación de significado a través del lenguaje, ayudan a moverse más allá de los aspectos mecánicos de decodificación y codificación. Igualmente, ambos estudios, exponen además las experiencias multiculturales que proveen instantes para el aprendizaje, tanto lingüístico como cultural y donde la colaboración intercultural resulta en la adquisición de prácticas discursivas sintácticas, semánticas, y pragmáticas.

De manera similar Li (2012) investigó el valor de las redes sociales entre quienes son inmigrantes y comparten la afición por el "manga" como una oportunidad para vincularse a comunidades sociales de familiares y amigos. Logrando acceso a materiales tanto en línea como impresos, información y recursos lingüísticos para aprender el idioma, ayudándoles a ser lectores y escritores exitosos, apoyando su literacidad en el nuevo idioma. Estos hallazgos discuten que las prácticas letradas realizadas en redes sociales, particularmente entre grupos minoritarios son importantes para quienes aprenden inglés como segunda lengua y se sienten marginalizados por sus compañeros para aprender el idioma y lograr éxito académico. Se encuentra coincidencia entre Li (2012) y Black (2005) en mantener un énfasis en la naturaleza social de la literacidad y el aprendizaje, lo cual permite a quienes tienen dificultades con la escritura tomar riesgos y experimentar con nuevos géneros de composición e interacción. Igualmente, en considerar el uso de la tecnología y las redes sociales para apoyar el desarrollo de comunidades de discurso donde los aprendices siguen de cerca la producción activa y la negociación de significado a través del lenguaje. También concuerdan Fukunaga (2006) y Li (2012) sobre el aporte que tiene acceder a diversos textos para desarrollo de la literacidad al ofrecer diferentes significados contextuales, lo que es un valor agregado, ya que la enseñanza de otras lenguas en el aula usualmente carece de estos elementos. 
En este nuevo panorama de nuevas prácticas letradas en otra lengua, los videojuegos en línea no son una excepción, ya que los jugadores hacen parte de una comunidad consumidora y productora de textos que requieren acciones colaborativas alrededor de metas comunes. Por ejemplo, el estudio cualitativo de Corredor y Gaydos (2014) con jóvenes residentes en Colombia argumenta que estas comunidades usan diferentes canales de comunicación como los blogs, los chats, y los medios sociales que les permiten estar juntos, intercambiar recursos y convertirse en bilingües. Su uso se parece a las prácticas formales de aprendizaje, pero comparte muchos aspectos de la manera en cómo la lengua es aprendida por hablantes nativos, es decir es situada en el contexto social y no puede ser separada de la identidad, por lo tanto, el aprendizaje de una segunda lengua no es visto fuera de su valor social. Sus resultados coinciden con Fukunagua (2006) y Li (2012) en que las prácticas de lectura y escritura en línea permiten nuevas formas de comunicación y de apoyar el desarrollo del lenguaje, de mantener y crear identidades a través de interacciones bilingües, en ambientes en línea que son socialmente relevantes y libres de limitaciones geográficas, al mismo tiempo que se fortalece la literacidad en otro idioma. En segundo lugar, y en programas de Licenciatura en idiomas extranjeros en Colombia, los docentes formadores han incluido en su enseñanza en el aula, las nuevas prácticas letradas que ejecutan los jóvenes fuera del aula, tales como los blogs, wikis y foros en plataforma virtual, investigando cómo fortalecen su aprendizaje no solo del idioma, sino también de otras áreas del currículo. Los estudios que se citan a continuación develan que su inclusión se ha realizado teniendo en cuenta que las nuevas prácticas letradas de los futuros docentes son espacios de trabajo y discusión, y más allá del propósito de hacer énfasis en el carácter técnico o novedoso de las tecnologías, los docentes les han brindado valor al carácter distintivo, y han tenido en cuenta que estas prácticas son participativas, entre otras de sus características.

Así, Insuasty y Zambrano (2010) en el contexto de una universidad pública usaron los diarios de campo para explorar cómo se puede potenciar la reflexión de los docentes en formación en un programa de lenguas extranjeras durante su práctica pedagógica y el blog para mantener discusiones sobre temas sugeridos por los docentes en formación. En cuanto al diario, aunque es usualmente reconocido como de uso individual, éste fue vinculado al aula por el docente formador con el propósito de guiar la reflexión sobre las experiencias particulares en el aula. Su uso permitió a los futuros docentes presentar su voz de manera espontánea y al mismo tiempo describir cómo enfrentaban esta nueva etapa de formación donde iban creando teorías de enseñanza y aprendizaje en sus contextos de enseñanza. Sin embargo, fue quizás la inclusión de un blog en esta experiencia de aprendizaje, lo cual facilitó la discusión sobre temas tales como la conducta de sus estudiantes en las aulas, ya que una vez que uno de los docentes en formación presentó una situación problema para que los estudiantes opinaran, y sus participaciones fueron espontáneas, expresando libremente opiniones y sentimientos frente a sus acciones en el aula, sin exigir el uso de un lenguaje académico. Se resalta ante todo que los participantes de este estudio lograron demostrar sus conocimientos sobre la enseñanza y saber pedagógico, además de mantener un sentido de comunidad que contó con la asistencia del docente para reflexionar.

En otro programa de formación de docentes, la wiki fue usada por Cote (2015) en su clase de investigación y sus resultados resaltan el valor de lo técnico, pero además su estudio demuestra el énfasis en el valor la interacción asincrónica voluntaria entre los participantes para compartir saberes y experiencias, a la vez que expresaron opiniones y puntos de vista que les permitieron participar activamente en la clase presencial. Se reportan además elementos colaterales del uso de la wiki como el desarrollo de elemento lingüísticos del otro idioma y se describen las interacciones voluntarias para expresar y contrastar opiniones y puntos de vista en un contexto de aprendizaje significativo. Insuasty y Zambrano (2010) y Cote (2015) reconocen el valor de usar nuevas prácticas letradas en línea para la construcción de conocimiento de forma colaborativa no siendo la herramienta lo esencial sino su uso. El valor del foro para incentivar la interacción entre contextos geográficos diferentes fue tema de estudio en las investigaciones realizadas por Clavijo, Hine y Quintero (2008); Clavijo y Quintero (2012), quienes lo usaron dentro de una plataforma virtual, reportando la participación, motivación e interacción que se generó en el idioma inglés entre estudiantes colombianos y canadienses de manera auténtica, lo que les permitió expresar gustos e intereses, además de facilitar intercambios interculturales y la creación de textos para una audiencia real con propósitos claros de comunicación. El aporte de estos estudios es el reconocimiento de los docentes sobre estas nuevas formas de leer y escribir como oportunidades de interacción con audiencias reales para comunicarse a través de distintos textos, facilitando los intercambios culturales que les permitieron mejorar su desempeño en el idioma.

Como se puede apreciar en los anteriores estudios, los docentes han tenido la iniciativa de vincular al aula lo que ellos consideran son algunas de las prácticas letradas de sus estudiantes fuera del aula, sin que esto signifique que se halla analizado en detalle lo que los estudiantes hacen por su cuenta para leer, escribir y comunicarse en otro idioma y que también les permite afianzar su aprendizaje. Así, mientras sus nuevas prácticas letradas permanezcan siendo desconocidas por sus docentes, difícilmente podrán ser integradas a las prácticas letradas del aula para que se dé realmente una transformación en las oportunidades de aprendizaje que se pueden elaborar entre estudiantes y docentes, y que además redunden en su futura labor docente. 


\section{METODOLOGÍA}

Este estudio se define como una investigación cualitativa, un estudio de caso que, de acuerdo con Hernández Fernández y Baptista, (2014), permite describir comprender e interpretar un fenómeno, en este caso, las prácticas letradas en lengua extranjera de 13 docentes en formación, en los semestres VII y VIII, en una Universidad Pública del Caribe Colombiano y cómo esas prácticas les permiten comunicarse y aprender en otro idioma. La técnica de recolección de información fue en primer lugar la entrevista a profundidad, realizando encuentros personales entre el investigador y los informantes, la cual se complementó con el uso de la fotografía participativa (Hernández et al. 2014), y fue un recurso de apoyo importante para registrar por parte de los mismos participantes, los usos habituales que hacían de la lectura y escritura en inglés fuera del aula. De igual manera, se trabajó con grupos focales para analizar sus interacciones, opiniones, sentimientos y percepciones sobre sus experiencias con la lectura y escritura fuera del aula para generar nuevos aprendizajes y comunicación con otros de maneras que el aula no les permite.

Así, una vez recabada la información se procedió a realizar una codificación de las transcripciones de las entrevistas a profundidad y los grupos focales utilizando el software Atlas.Ti, identificando frases cortas o párrafos que se consideraron tenían una significación destacable en relación al objetivo de estudio, asignándoles códigos que compilaran el significado emergente. Habitualmente este paso recibe el nombre de codificación abierta desde la teoría fundamentada, ya que se emprendió una lectura intensiva de los datos, tratando de no imponer una interpretación desde las teorías preexistentes únicamente, y ante todo identificando: ¿Qué estaba sucediendo en relación a las prácticas de lectura y escritura en inglés de los participantes fuera del aula?, ¿Qué estaban haciendo con ellas?, ¿Qué las distinguía? ¿Qué querían decir sus acciones y respuestas?. De este primer análisis surgió una amplia lista de códigos que se pensaba podían responder al objetivo de la investigación y algunos ejemplos son señalados en el siguiente ejemplo:

Tabla 1: Ejemplo de codificación abierta

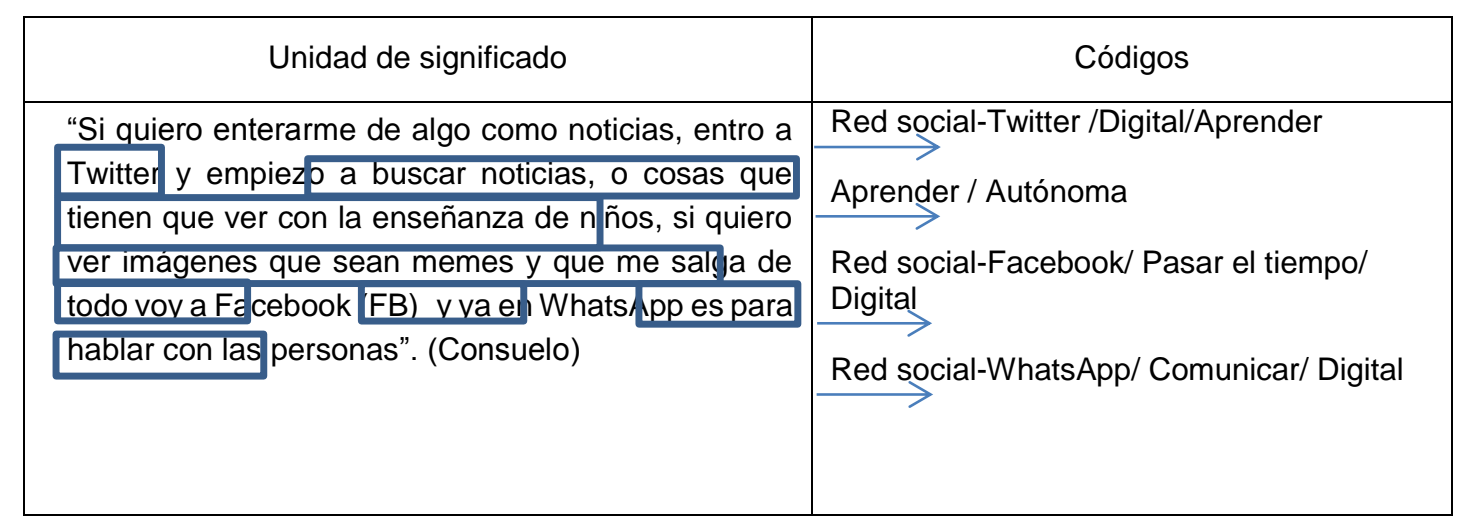

Luego realizando una comparación constante de las unidades de significado y conectándolas conceptualmente se generaron tres categorías: a) Prácticas letradas personales, b) Usos de las prácticas letradas personales, c) Características distintivas. Se tuvo en cuenta al nombrar la categoría prácticas letradas personales, que usualmente los participantes leían y escribían en las redes sociales, y éstas les permitían presentar sus opiniones, sentimientos o indagar por su cuenta en su tiempo y espacio. Sus testimonios igualmente señalaban que sus prácticas letradas personales tenían usos particulares dentro de su vida diaria para comunicarse con otros en el idioma inglés y aprender sobre diferentes temas, además de usarlas para pasar el tiempo. De otra parte, sus prácticas se distinguían por ser usualmente digitales, multimodales, creativas, colaborativas, autónomas y de acuerdo a sus necesidades e intereses. Así, el siguiente paso correspondió a una codificación axial y las categorías fueron agrupadas en un tema que se le denominó: Mis experiencias personales con la lectura y escritura fuera del aula para comunicar y aprender, y del cual se da cuenta en este artículo.

\section{RESULTADOS Y DISCUSIÓN}

Los resultados expuestos dan cuenta de las experiencias personales que mantienen los participantes con la lectura y escritura fuera del aula, señalándose que el uso que hacen de la lengua escrita en inglés tiene una orientación sociocultural, ya que leer y escribir también hace parte de su vida personal fuera del aula. Es decir y concordancia con el marco teórico de los Nuevos Estudios de Literacidad (NEL) (Street, 1984, 1995; Gee, 1986; Barton y Hamilton, 1998) sus declaraciones reconocen, aún si es de manera inconsciente, que su literacidad es esencialmente social, ya que en su vida diaria leen y escriben mientras participaban en actividades sociales más amplias. Así, se identificó la inclusión no solo procesos abstractos o actos de escritura sin propósito, sino de oportunidades sociales situadas que les facilitaban comunicarse, pensar y 
aprender. Queriendo decir que más allá de las palabras y temas ligados a las experiencias de sus docentes, ellos por su cuenta generan experiencias con la lectura y la escritura con diferentes tipos de textos, dando lugar a un panorama multimodal, en distintos contextos y con diversos grupos. Por lo anterior, dentro del panorama letrado expuesto se sugiere que entre los participantes se han multiplicado las oportunidades de comunicación con otros, en distintos contextos geográficos, incluso para profundizar sobre diversos temas que pueden estar también relacionados con el aprendizaje o la enseñanza del idioma inglés, o simplemente para pasar el tiempo y entretenerse. En general, sus prácticas letradas son menos convencionales y el giro digital en el cual se hallan ha variado su mundo social, llevándolos a mantener fuera del aula una lectura y escritura que ha pasado de la página a la pantalla, y que les demanda ante todo saber responder a iconos animados, hipertextos, efectos de sonido y navegar en rutas entre y dentro de las pantallas.

Así, lo más importante además de saber manejar lo nuevo de lo técnico en sus nuevas prácticas letradas, es que ante todo los participantes aprecian su "carácter distintivo" por la colaboración y participación que les generan (Lankshear y Knobel, 2014, p.98), lo cual les facilita comunicarse de manera natural y espontanea en otro idioma y esto finalmente les aporta a su aprendizaje. Desde la evidencia se tomaron como ejemplo algunas de las respuestas de los estudiantes sobre todo en relación a qué leían y escribían en sus redes sociales porque fueron las que más frecuentemente reportaron usar para comunicarse con otros. Éstas les permiten crear un usuario y un perfil de datos para compartirlo con otros a través de categorías, grupos etiquetados, personales o ligados a su perfil profesional o personal. Su uso como se describe no es solo un asunto para pasar el tiempo, sino además una oportunidad de leer y escribir, para comunicarse e interactuar en el idioma que aprenden, aún si geográficamente pareciese imposible. Por ejemplo, Esperanza y Angie reportaron:

\begin{abstract}
"Yo tengo un amigo de Irlanda y me comunico por Facebook, él es una persona muy conocedora y muy interesada sobre las culturas y la historia, así que me ha ilustrado mucho sobre como es el comportamiento de su país, cómo ha evolucionado, por qué hay Irlanda del Norte, por qué hay Irlanda del Sur, ósea muchas cosas que yo no sabía, porque yo antes pensaba pues que toda Irlanda pertenecía al Reino Unido, y bueno él me ha explicado mucho por qué ha llegado a ese punto, el conflicto que hay actualmente, que hay muchas cosas que se parecen a la situación que nosotros vivimos acá en Colombia con los grupos armados." "En Facebook se dio una conexión muy fuerte con un chico de la república Cheka. Él tiene nivel C1. Lo que hacemos es solo hablar en inglés, porque él no entendería español y ni yo su idioma. El inglés es el único medio para comunicarnos. A través de la comunicación se ha dado cierta química. Hablamos sobre el tratamiento del agua porque acá existe un mimetismo sobre el tema de que eso es muy costoso por allá. Entonces él me explicó sobre el tratamiento del agua que es diferente, me explicó en términos químicos y científicos y yo le entendí. También le compartí imágenes de la comida típica y él también me compartía de su cultura y llegó a enviarme mitos y cuentos cortos de su tradición Cheka en inglés".
\end{abstract}

La evidencia seleccionada devela que interactuar en redes sociales para estos estudiantes no es solo una oportunidad de recreación, sino también una ocasión para entablar comunicación e intercambio cultural a través de las conversaciones que se mantienen con quienes usan el idioma inglés, aún si no son nativos, lo que les permite negociar significados. Aunque, el potencial de estas nuevas prácticas letradas puede ser desconocido por el aula de clase, se resalta el énfasis social que los participantes le dan a su literacidad, la cual les permite interactuar con otras personas que conocen y utilizan las mismas prácticas letradas, logrando un acompañamiento, retroalimentación, y al mismo tiempo asumiendo roles de pares, colegas e incluso de expertos para acompañar el proceso de composición de los textos que crean.

Igualmente, sus interacciones se pueden definir como flexibles, teniendo en cuenta que ante todo buscan comunicarse, y por tanto evitan ser tan selectivos respecto a sus audiencias, y escogen las redes sociales porque les facilita expresarse libremente, son atractivas y representan nuevas formas de comunicar y hallar información cultural por ellos mismos. Así, los participantes describen la oportunidad de negociar significados lo cual involucra el uso del idioma, donde hay diálogos genuinos y esto coincide con lo sugerido por Blattner y Fiori (2009, p.22) en que lo que se evidencia en redes sociales y en Facebook en particular, es una interacción que facilita la competencia socio pragmática a través de intervenciones significativas, ya que interactúan con hablantes nativos.

Los resultados expuestos demuestran que los participantes comprenden el significado de literacidad como práctica social, y esto justifica la necesidad de capitalizar las oportunidades académicas y sociales que estos contextos tienen por ofrecerles, ya que si los jóvenes las usan fuera del aula seguramente las pueden acoger dentro de ella. En otras palabras, significa que los docentes pueden promover relaciones positivas entre estudiantes y desarrollar la posibilidad de colaborar con otros en una lengua extranjera dentro del mismo grupo de aula. Buscando ante todo que los actos de lectura y escritura sean creativos y que impliquen la comprensión de la realidad de parte de los estudiantes y no solo que se realice una movilización de prácticas que al llegar al aula pierdan su carácter distintivo. 
Alrededor de estas nuevas prácticas letradas los participantes igualmente presentaron evidencia de que desarrollan comunidad, lazos de amistad, solidaridad sin proponérselo, a través de las frecuentes interacciones sociales en las redes sociales, las cuales a la larga les permiten colaborar entre ellos mismos, y apoyar el aprendizaje del idioma. Por ejemplo, Carmen reportó ser miembro de un grupo de fans de un joven camarógrafo, a quien sigue desde hace un tiempo y le envía diferentes mensajes por la gran admiración que le provoca su trabajo artístico. Como resultado, ella misma considera que su vinculación al grupo, le ha permitido hacer parte de una comunidad que comparte no solo los mismos intereses sobre el tema que los reúne, sino que también ha construido relaciones personales que a la larga le permiten participar de la vida de quienes hacen parte del grupo:

"Mantengo una amistad con dos chicas, nos comunicamos en Facebook e Instagram. Ellas dos son de Inglaterra, una se llama "Jay" y la otra se llama "Lory", y viera usted, vivimos tan lejos y así nos comunicamos. Hace poco una de ellas se enfermó y estuvimos pendientes porque ella sufre de depresión. Luego de superar esta etapa ellas dos se fueron de viaje y me contaban todo lo que hacían. Yo estaba pendiente de lo que contaban pues eran muchas cosas nuevas para preguntar".

Lo anterior implica que quienes hacen parte de los grupos saben que algunos son extranjeros y están aprendiendo el idioma y de su cultura, por eso los participantes son conscientes de valorar el apoyo que sus nuevos amigos les ofrecen a través de las redes sociales de manera voluntaria sobre diferentes temas, entre esos los culturales. Estas interacciones para los docentes pueden sonar un tanto extrañas, pero de acuerdo a Wilbur (2008) lo que sucede entre los jóvenes es factible, ya que ellos tienen actitudes más flexibles y familiares que les permiten de manera más espontánea crear oportunidades de comunicación. Al final, a través de la escritura de distintos textos como también lo sugiere Maritza y se muestra en la figura 1 , intercambian información, opiniones y comparten sobre diversos elementos culturales con sus nuevos amigos:

"Estas son mis conversaciones con Matt. Me envió una imagen y no sabía que era. Todo lucía sabroso y él me escribió que era clamato, es un jugo de tomate picante. El estaba en Canadá. Pero él viaja mucho por el mundo. También me envío el estado del clima y me envió la temperatura y ahí hablamos. Yo en ese momento le envié un mapa de donde yo estaba y le dije que hacía. Le hablé un poco de mi ciudad".

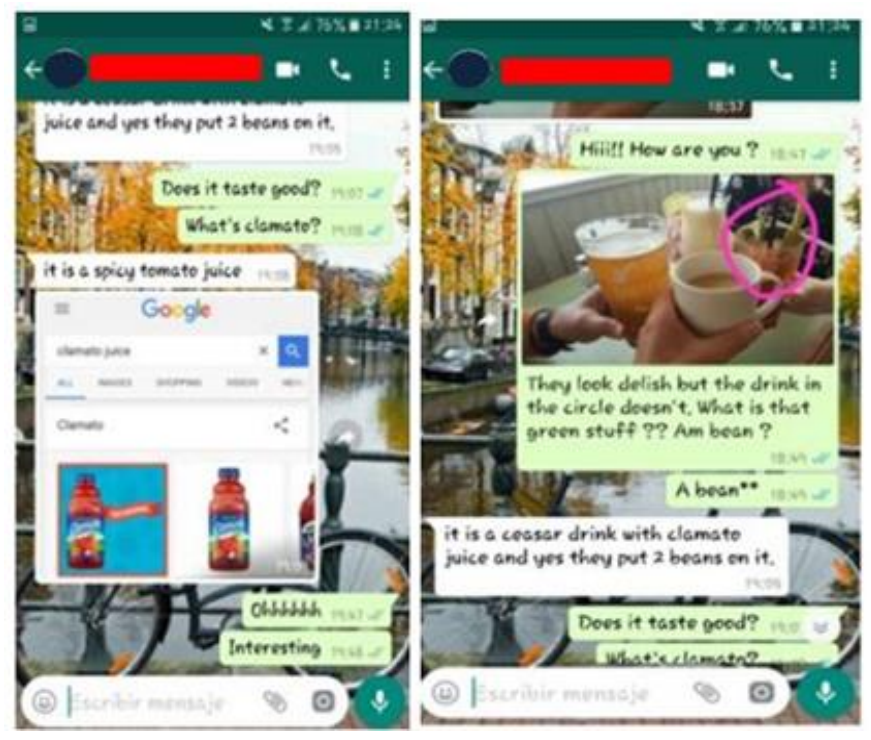

Fig. 1: Conversaciones en WhatsApp

Así, estos apartados resaltan el valor que los participantes le dan a lo que hacen a través de las redes sociales. En este sentido y como sugiere Li (2012) para quien aprende otro idioma esto es reconocido como una oportunidad para vincularse a comunidades, las cuales proveen acceso a nueva información y recursos lingüísticos para aprender, ayudándolos a ser lectores y escritores exitosos, apoyando su literacidad en el nuevo idioma. Aunque la evidencia no reporta que los participantes estuviesen buscando crear comunidad o establecer relaciones frecuentes con sus miembros, si sugiere que en la medida que la comunicación en línea se hace permanente, ellos mismos identifican que les ayuda al desarrollo de su literacidad en inglés porque no solo están decodificado textos, sino que están comunicándose y al hacerlo comparten diferentes textos que les permiten interpretar significados y comprender cómo se usa el idioma de manera auténtica.

Por supuesto, para interpretar los textos, los jóvenes activan conocimientos previos, hacen una relación entre el tema y el conocimiento que ya poseen, infieren, notan detalles importantes y los organizan, entre 
otros. Igualmente, demuestran conocimientos y habilidades que son específicas a las nuevas formas de leer y escribir como leer los textos de izquierda a derecha, de arriba abajo o de izquierda a derecha, y usar nuevos saberes digitales para crear y adaptar nuevos textos, entre otros. Dando además sentido al texto lingüístico, visual y oral en conjunto para interpretar lo que leen y escriben y haciendo uso de rasgos de prosa espontanea de manera cuidadosa, lo que les permite no solo acceder a la información, sino también construirla para ser autores y comunicarse con otras personas. Al escribir durante sus intercambios son conscientes de que deben recurrir a nuevos recursos y saberes digitales para modificar y crear nuevos textos. También y siguiendo a Kern (2000, p.37) en lo que hacen no se vuelven letrados en otro idioma solo porque tengan un nivel de suficiencia en leer y escribir en el idioma, sino porque "son herramientas para pensar y aprender, y ampliar su visión de mundo y de ellos mismos". Por su puesto, en la construcción e interpretación de nuevos textos, los participantes reconocen que necesitan usar diccionarios y nuevas aplicaciones digitales que se hallan en línea para hacer más natural su comunicación. Estas les brindan acceso a diferentes significados de las expresiones o el vocabulario que desconocen, y les permitan editar textos rápidamente mientras se comunican, como reportaron en el grupo focal Carmen y Consuelo:

"Recuerdo que incluso una vez en el grupo que participó hicieron un comentario y yo lo cogí muy literal, y yo dije para mí: pero, ¿eso qué es?, entonces enseguida busqué en el diccionario on line, y vamos a ver que era como un phrasal verb y yo dije aahhhhh, entendí. Cuando yo lo leí primero yo dije: no entendí nada, pero después ya busqué la frase, y si era un chiste y yo como que dije ahora si entiendo, pude entonces buscar una imagen al respecto y enviar un mensaje".

"Cuando uno se comunica en las redes sociales, no se trata solo de escribir por escribir, de pronto aparece algo que uno no sabe, y eso pasa bastante porque no somos nativos, pero se busca rápidamente el significado de lo que están diciendo, la idea es no perder el hilo de la conversación. Por su puesto hay ocasiones en las que surgen palabras raras pero se buscan, eso no es problema (ríe) hay muchas maneras de hallarlas. Sin tener que preguntar, ese es el último recurso".

Desde la evidencia se señala el uso de formas sofisticadas para responder a lo que otros han dicho, y se observa que se favorece una interacción continua y dialógica con otros lectores de diversos contextos. De otra parte, al interactuar con otras personas el potencial de discusión inmediata de las redes sociales, les ayuda enfatizar la naturaleza social de la escritura y resalta la importancia de la retroalimentación de pares, colegas y expertos en el proceso de composición. Estas oportunidades son además valiosas para los participantes por lo auténtico de cada momento, por ejemplo Maritza reportó:

"Mi mejor oportunidad para aprender el idioma de manera auténtica es con Mat. Él es mi amigo en WhatsApp y me agregó en un grupo donde él también tiene amigos alrededor del mundo porque habla cinco idiomas, el inglés, francés, portugués, alemán y español; entonces en ese grupo uno encuentra de todo en varios idiomas. Él escribe y dice que es para mis amigos que están aprendiendo inglés y coloca un cuento e imágenes, siempre es bastante extenso y todos preguntamos o comentamos que significa esto o aquello, incluso algunos cambian el final".

En el caso de la red social WhatsApp se facilita el uso de múltiples modos de representación, el acceso a una variedad de posibilidades semióticas para ofrecer sentido y lograr una intención retórica. Quienes escriben lo hacen de manera sofisticada en actividades de composición ya que deben sintetizar lo que dicen otros, involucrándose en interacciones dialógicas con otros lectores y usando los recursos disponibles en la comunidad en la medida que leen, editan y rediseñan textos. Al final, los participantes se permiten mejorar el aprendizaje del idioma, al mismo tiempo que mantienen relaciones sociales, dejando ver que los textos que producen son creativos. Sobre esto último, Carmen también comentó que dentro del grupo que participa con sus amigas siguen a un actor de una serie de televisión. Su afición empezó por la lectura de un libro, el cual le pareció aburrido y nunca leyó, y por eso decidió solo ver la serie en televisión, y luego hacer parte de un grupo de fans en una red social:

"My Mad Fat Diary, eso es una serie, es British. Entonces, yo no sabía nada de la serie, sino que yo una vez vi una foto en Facebook de la serie y me pareció interesante, y yo dije, vamos a ver, y la vi, y la daban por I Sat, me la vi. El libro nunca me lo leí, porque el libro me lo empecé a leer pero es como aburridito, pero la serie si me la vi, entonces de ahí me enamoré del actor (risas), una fan girl, entonces lo seguí en Twitter y seguí en Facebook una página de seguidores también, yo soy una fangirl".

Al definirse como una "fangirl", la participante deja saber que el objeto de afición y por el cual lee es para saber sobre los actores y las series. Ella ha entrado a hacer parte de un espacio donde existe una afinidad y tal y como lo describe Gee (2004, p. 85) ahí interactúan tanto "aprendices como expertos y todos los demás lo que hacen es compartir una pasión". Es tan intensa su pasión por este tema que incluso se ha comunicado con el actor y le ha escrito: "Empecé a seguirlo ahí, entonces le escribí porque fue el día del cumpleaños de 
él, luego escribí una carta corta". Dentro de la evidencia que trae, ella muestra la foto de la carta que le envío y los mensajes que le ha dejado en Twitter, los cuales le escribió para su cumpleaños y otro que le envío un día cualquiera:
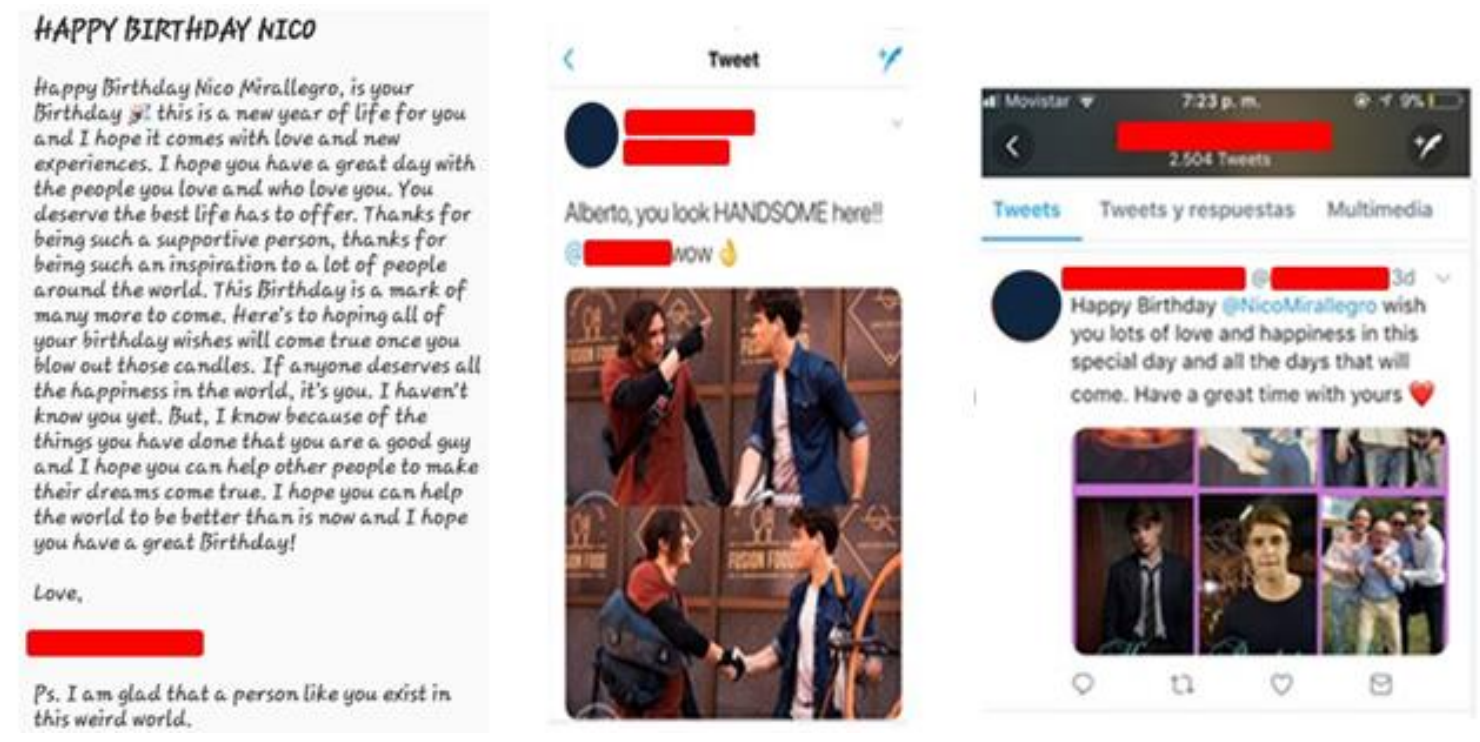

Fig. 2: Carta en Facebook y mensajes en Twitter

Es decir que la participante, hace lo posible por comunicarse con el actor que admira y le deja saber su opinión sobre su trabajo, por eso diseña textos que no escribe solo para ella, sino que los pública como se muestra en la figura 2. Lo hace de manera independiente y creativa, su interés es involucrarse en conversaciones en el idioma inglés con otros alrededor del mundo, mostrar lo que siente y piensa. Tal vez no recibe respuesta del actor, sin embargo entre sus nuevas amigas quienes son extranjeras este es un tema de conversación. Es además una oportunidad para socializar y usar la lengua escrita en contextos situados de manera estratégica y autónoma para expresar sus opiniones, sentimientos, intercambiar información, desarrollar y mantener relaciones sociales en un idioma que aprende en el aula de clase. Al hacerlo demuestra que su nueva práctica letrada le permite ante todo comunicar lo que piensa de manera regular, demostrando que aprecia el valor de la lengua escrita, la cual utiliza con otros modos semióticos, y esto le facilita participar en un mundo social de actores y fans. Su iniciativa también señala su deseo de comunicarse a través del idioma y aprender sobre otros temas con sus nuevos amigos, convirtiéndose leer y escribir en las redes sociales un asunto que va más allá de solo pasar el tiempo, y se convierte en su mejor oportunidad para poner en práctica lo que ha aprendido en el aula de clase. Aunque Carmen habita en un contexto donde el idioma difícilmente se habla o escribe de manera regular fuera del aula, por su cuenta ha encontrado otras posibilidades para usarlo de manera espontánea, derrumbando barreras lingüísticas y culturales.

De la misma manera, los intercambios culturales son parte de las interacciones sociales, ya que de acuerdo a los participantes mientras en el aula es inusual abordar este tema, a no ser que sea con un objetivo pedagógico mientras ven videos o leen textos escritos para discutir qué diferencias se aprecian con la propia cultura, en sus conversaciones en redes sociales esto es cotidiano. Es decir que acceder al aprendizaje de elementos culturales es natural y más aún si permite intercambiar información sobre su propio país, lo que incluso les provee mejor comprensión de su propia cultura como lo reportaron Carmen y Maritza:

"En Instagram ahora sigo a un amigo que viaja por diferentes partes ciudades, y es como crítico de comida, es como chef, entonces ha ido a Tailandia, Francia, ha ido a muchos lugares, a Grecia, la última vez ellos tuvieron en Grecia los tres, el actor, su hermano y el amigo. A través de esto he aprendido mucho vocabulario, costumbres de estos países, hay palabras que yo por lo menos nunca había pensado que podía usar, y si ahora he visto...es posible contrastar y mirar las diferencias en muchos aspectos como la comida, por ejemplo de nuestro país, de eso les he comentado".

"En mi caso yo me comunico con alguien que es un profesor de matemáticas en una institución pública, entonces también nos hablaba a mis amigas y a mi sobre los estudiantes, a través de WhatsApp, sobre cómo estaban distribuidos los salones en Canadá, cómo se sentaban, que iban de dos en dos, que tenían un mapa, me pareció muy interesante esa vida escolar. El continuamente me cuenta y me enseña nuevas cosas de su cultura en Canadá, sobre la comida y las costumbres y bueno yo también sobre mi país y eso me hace incluso investigar para contarle". 
En general, los apartes presentados describen una participación espontánea en redes sociales que facilita usar el idioma inglés de manera frecuente y auténtica, teniendo en cuenta que los participantes viven en un contexto donde el idioma es enseñado en el aula de clase. Sus interacciones además demuestran una gran iniciativa por mantener encuentros sociales y culturales por su propia cuenta, buscando siempre oportunidades de comunicarse e interactuar a través de lo visual, un sonido, una palabra, un movimiento, animaciones y dimensiones espaciales, para lograr un efecto en los textos (Rowsell y Walsh, 2012). Significa además, que poseen niveles de autonomía para realizar tales tareas y todo con el objetivo de llegar a conocer a otros que hablan el idioma y usarlo de manera espontánea. Entre todos existe un esfuerzo para mantener una comunicación en el idioma, el cual redunda de manera positiva y es valioso para su aprendizaje no solo lingüístico sino cultural. Así, los resultados expuestos coinciden con los estudios de Clavijo, Hine y Quintero (2008) y Clavijo y Quintero (2012), ya que en sus estudios los estudiantes desde dos contextos diferentes como Canadá y Colombia también construyeron y nutrieron a través de foros virtuales una relación personal. Con la diferencia, por supuesto de que este proceso fue guiado por los docentes, quienes planearon realizar tareas pedagógicas tomando ventaja de las interacciones construidas entre estudiantes de las dos culturas y en este estudio los participantes lo hicieron siempre por su cuenta. Sin embargo, no puede dejar de notarse que por productivas que parezcan las interacciones de los participantes, y teniendo en cuenta que este es un tema relativamente nuevo dentro de sus vidas, podría existir un papel más activo por parte de los docentes en Programa de Licenciatura, para enseñarles al menos en un principio a encausar sus conversaciones sobre temas culturales, económicos, educativos o políticos. Lo anterior teniendo en cuenta como anota Helm (2013) que existe una preocupación acerca de aquellos intercambios culturales donde la comunicación no es moderada, y los estudiantes tienden a hablar de temas triviales negándose a retar las ideas de los demás, algunas veces perdiendo la posibilidad de tener otras oportunidades de aprendizaje.

De todas formas y en lo que se evidenció, leer y escribir es un asunto nuevo desde su carácter técnico y distintivo, ya que implica nuevas posibilidades de participación con diferentes comunidades, que abre nuevas posibilidades de comunicar significado con diferentes personas e intereses. Por esta razón se considera que las redes sociales reportadas por los participantes como Twitter, Facebook, Instagram y WhatsApp son nuevas prácticas letradas donde además de lo novedoso de lo digital, ocurrió la interpretación y creación de significado a través de diferentes tipos de textos a los que los participantes tuvieron acceso, y les permitió sostener comunicación con personas y grupos que de otra manera no sería posible en el contexto donde viven. Lo cual coincide con Espitia y Clavijo (2011) en el potencial que hallan los estudiantes para interactuar con diferentes personas, adquirir nuevo conocimiento, aumentar su motivación hacia el aprendizaje del idioma y colaborar con otros en espacios digitales. Su actitud positiva tiene que ver con el hecho de que involucran nuevas formas de leer y escribir que no podrían hacer con lápiz y papel, donde además cuentan con audiencias reales, propósitos claros de comunicación, y participan en un ambiente multimodal donde aprenden a negociar significados a partir de todos los textos que comparten. Es decir que entre quienes estudian el idioma inglés, no se trata de un asunto de solo pasar el tiempo, sino también de tener una oportunidad para fortalecer el aprendizaje del idioma fuera del aula. Por lo que se concuerda con Rowsell y Walsh (2012) en que si los estudiantes están usando fuera de la escuela nuevas prácticas sociales, entonces es bueno preguntarse si estos modos de comunicación pueden usarse en la escuela para comprometer a los estudiantes con el aprendizaje. Es por lo tanto imperativo que los docentes de una vez por todas, Hconozcan y valoren lo que los jóvenes saben hacer con la lectura y escritura fuera del aula y se entienda la manera como estas experiencias también contribuyen a su literacidad académica. De hacerlo se podrían establecer más puentes que distancias entre: las prácticas letradas de fuera del aula con las del aula de clase. Facilitándose igualmente, el proceso enseñanza y aprendizaje del idioma inglés en un contexto donde el idioma se enseña como lengua extranjera.

\section{CONCLUSIONES}

La perspectiva social en la que este estudio se enmarcó, puso el acento en qué hacían los futuros docentes de inglés con sus nuevas prácticas letradas en el idioma inglés en sus contextos cotidianos, y permitió identificar que leer y escribir son actos de aprendizaje y comunicación realizados con textos multimodales que les ofrecen algo más de que hablar en el idioma que aprenden, les brindan la posibilidad de tomar posturas, y crear nuevos textos ante temas que son de su interés. De esta manera los participantes demostraron a través de sus respuestas que fuera del aula mantienen una comunicación activa, dinámica, multimodal y son capaces de presentarse ante los demás de manera positiva, colaborar y negociar significados en el idioma inglés de manera autónoma. De otra parte, si bien existe novedad en el aspecto técnico de sus nuevas prácticas letradas, y esto innegablemente las hace más atractivas en comparación con aquellas que son más formales o del aula de clase, los participantes mostraron evidencia del valor que le otorgan al lenguaje escrito, en combinación con otros modos como una imagen, una fotografía, un audio o un video para dar sentido a sus mensajes, interpretarlos, interactuar y crear textos para audiencias reales. Así, de manera creativa, autónoma, siguiendo una organización y normas propias de los espacios utilizados, aprenden a comunicarse 
con otros, respetando las convenciones propias del idioma. Existe por lo tanto, un reconocimiento del "carácter técnico y distintivo" que poseen sus nuevas prácticas letradas, y al que hace referencia Knobel y Lankshear (2014, 2014, p 98), y esto les facilita escoger por si mismos sus experiencias de lectura y escritura para comunicarse, realizar intercambios culturales, aprender y colaborar con otros, ya sean hablantes nativos del idioma inglés o con quienes también lo aprenden como lengua extranjera, de maneras que el aula quizás no les permite, no solo porque sus nuevas prácticas letradas sean digitales y multimodales, sino porque rompen los esquemas del aula. Siguiendo a Barton y Hamilton (1998, p. 3) son prácticas sociales donde su contexto social les da significado y donde además los participantes asumen roles similares a una conversación personal, y por eso no se tiene que levantar la mano o esperar que se les dé permiso para hablar.

Igualmente, la evidencia señala que los participantes reconocen el valor a la lectura y escritura no solo como dos habilidades aprendidas de manera independiente, sino como un proceso dialógico de dar significado, adquiridas y enmarcadas en contextos sociales, por lo cual leen textos que otras personas publican, son activos y responden con sus propios textos para opinar. Estas son actividades que demandan poner en función conocimientos para leer y escribir en otro idioma, pero también nuevas habilidades para pensar y actuar con los textos multimodales que encuentran. Al final, sus conversaciones les ofrecen un propósito real que alienta que se involucren intensamente con el idioma, y participen en comunidades globales usando recursos compartidos con amigos, donde leer y escribir pueden ser una oportunidad para hacer conexiones entre la gramática, el discurso, el lenguaje, el contenido y la cultura, más que una oportunidad para solo mejorar dos habilidades independientes.

\section{REFERENCIAS}

Acosta, Y. y D. Poveda, Formación didáctica de profesores de inglés a través de comunidades de aprendizaje, En Congreso Iberoamericano de Ciencia y Tecnología, Innovación y Educación, 1-18, Buenos Aires, Argentina, Noviembre (2014)

Barton, D. y C. Lee, Redefining vernacular literacies in the age of Web 2.0, doi.10.1093/applin/ams009, Applied linguistics, 33(3), 282-298 (2012)

Barton, D. y M. Hamilton, Local literacies: Reading and writing in one community, $1^{\text {st }}$ Ed., 3-22, Routledge, Londres, Inglaterra (1998)

Black, R., Access and affiliation: The literacy and composition practices of English-language learners in an online fanfiction community, doi.10.1598/JAAL.49.2.4, Journal of adolescent \& adult literacy, 49(2), 118-128 (2005)

Blattner, G. y M. Fiori, Facebook in the language classroom: Promises and possibilities, International Journal of Instructional Technology and Distance Learning, ISSN: 1550-6908, 6(1), 17-28 (2009)

Clavijo, A. y L. Quintero, Una experiencia de formación inicial de docentes de inglés para la inclusión de las TIC en la enseñanza de lenguas, Revista Folios, ISSN: 0123-4870, 36, 37-48 (2012)

Clavijo, A., N. Hine y L. Quintero, The Virtual Forum as an Alternative Way to Enhance Foreign Language Learning. Profile: Issues in Teachers' professional development Journal, ISSN: 1657-0790, 9, 219-236 (2008)

Corredor, J. y M. Gaydos, Language Games. Tomado de H.R., Gerber y S.S. Abrams (Eds.), Bridging Literacies with videogames, Gaming Ecologies and Pedagogies Series, 103-128, Sense Publishers, Rotterdam, The Netherlands (2014)

Cote, P.G., Engaging Foreign Language Learners in a Web 2.0-Mediated Collaborative Learning Process, doi.org/10.15446/profile.v17n2.47510, Profile: Issues in Teachers' Professional Development, 17(2), 137-146 (2015)

Espitia, I. y A. Clavijo, Virtual Forums: A Pedagogical Tool for Collaboration and Learning in Teacher Education, doi.org/10.14483/issn.2248-7085, Colombian Applied Linguistics Journal, 13 (2), 29-42 (2011)

Fukunaga, N., "Those anime students": Foreign language literacy development through Japanese popular culture, doi.org/10.1598/JAAL.50.3.5, Journal of Adolescent \& Adult Literacy, 50(3), 206-222 (2006)

Gee, J.P., Lo que nos enseñan los videojuegos sobre el aprendizaje y el analfabetismo, 85, Ediciones Aljibe y Enseñanza Abierta de Andalucía, Málaga, España (2004)

Gee, J.P., Social Linguistics and Literacies: Ideology in Discourses. Routledge Falmer, Londres, Inglaterra (1996)

Helm, F., A dialogic model for telecollaboration. Bellaterra Journal of Teaching \& Learning Language \& Literature, ISSN: 2013-6196, 6(2), 28-48 (2013)

Herazo, J.D., S. Jerez y D. Lorduy, Opportunity and incentive for becoming bilingual in Colombia: Implications for Programa Nacional de Bilingüismo, Íkala, revista de lenguaje y cultura, ISSN: 0123-3432, 17(2), 199-213 (2012)

Hernández S., C. Fernández y P. Baptista, Metodología de la investigación, 6ª Ed., 468-506, McGraw-Hill, México D.F., México (2014)

Insuasty, E. y L. Zambrano, Exploring reflective teaching through informed journal keeping and blog group discussion in the teaching practicum, Profile Issues in Teachers Professional Development, ISSN: 1657-0790,12(2), 87-105 (2010) 
Jerez, S., S. Mercado y M. Viloria, Teacher Candidates and their literacy practices in the teaching practicum. "Congreso Internacional de Lectura y Escritura en la sociedad Global, 41-51, Barranquilla, Colombia, Junio (2015)

Kern, R., Literacy and language teaching, $1^{\text {st }}$ Ed., 13-41, Oxford University Press, Nueva York, USA (2000)

Knobel, M. y C. Lankshear, Studying New Literacies, doi.org/10.1002/jaal.314, Journal of Adolescent \& Adult Literacy, 58(2), 97-101(2014)

Kress, G., Literacy in the new media age, Psychology Press, Routledge, Londres, Inglaterra (2003)

$\mathrm{Li}$, G., Literacy engagement through online and offline communities outside school: English language learners' development as readers and writers, doi:org/10.1080/00405841.2012.726061, Theory into Practice, 51(4), 312-318 (2012)

López, G. y C. Pérez, Debates actuales en torno a los conceptos "alfabetización", "cultura escrita" y "literacidad" [Current discussions on the concepts of "literacy," "written culture" and "literacy"]. Tomado de A. Carrasco y G. López (Eds.), Lenguaje y educación: Temas de investigación educativa en México [Language and education: Issues of educational research in México], 23-49, Colonia del Valle, México (2013)

Lorenzatti, M., Procesos de literacidad en jóvenes y adultos: convergencia de instituciones y sujetos, doi.org/10.5007/2175-795X.2014v32n1p39, Perspectiva, 32(1), 39-62 (2014)

Mora, R., Critical Literacy as Policy and Advocacy, doi.org/10.1002/jaal.329, Adolescent y Adult Literacy, 58(1), 16-18 (2014)

Mueller, P. y D. Oppenheimer, The pen is mightier than the keyboard advantages of longhand over laptop note taking, doi:10.1177/0956797614524581, Psychological science, 25(6), 1159-1168 (2014)

Rowsell, J. y M. Walsh, Repensar la letroescritura para nuevos tiempos: multimodalidad, multiliteracidades y nuevas alfabetizaciones, doi.org/10.14483/udistrital.jour.enunc.2015.1.a10, Enunciación, 20(1), 141-150 (2015)

Street, B., Literacy in theory and practice. Cambridge University Press, Londres, UK (1984)

Street, B., What's "new" in New Literacy Studies? Critical approaches to literacy in theory and practice. Current issues in comparative education, 5(2), 77-91(2003)

Viñao, A., Alfabetización e ilustración, diez años después (de las evidencias directas a las indirectas), Bulletin hispanique, 100(2), 255-269 (1998)

Wilbur, D., iLife: Understanding and connecting to the digital literacies of adolescents. Tomado de Hinchman, K.A., Sheridan, H.K. (2008) Best Practices in Adolescent Literacy Instruction: Solving problems in the teaching of literacy, pp. 57-77, Guilford Press, New York, USA (2008)

Zavala, V., La Literacidad, o lo que la gente" hace" con la lectura y la escritura, Textos de Didáctica de la Lengua y la Literatura, (47), 71-79 (2008) 